\title{
Tip 2 Diyabetli Hastalarda Kan Glukoz Seviyesi ile Kas Gücü, Propriosepsiyon ve Vücut Kompozisyonu Arasındaki İlişki
}

\author{
Zahide Betül TAYFUR ${ }^{1} \oplus \square$, Esra ATILGAN ${ }^{2} \oplus$ \\ ${ }^{1}$ İstanbul Medipol Üniversitesi, Sağlık Bilimleri Enstitüsü, Fizyoterapi ve Rehabilitasyon Anabilim Dalı, Güney Kampüsü, Kavacık, İstanbul, Türkiye \\ ${ }^{2}$ İstanbul Medipol Üniversitesi, Sağlık Bilimleri Fakültesi, Fizyoterapi ve Rehabilitasyon Bölümü, Güney Kampüsü, Kavacık, İstanbul, Türkiye \\ Bu makaleye yapılacak atıf: Tayfur ZB, Atılgan E. Tip 2 Diyabetli Hastalarda Kan Glukoz Seviyesi ile Kas Gücü, Propriosepsiyon ve Vücut Kompozisyonu Arasındaki İlişki. \\ Türk Diyab Obez 2020;3: 207-213.
}

\begin{abstract}
ÖZ
Amaç: Tip 2 diabetes mellitus (Tip 2 DM) tanılı hastalarda kan glukoz seviyesi ile kas kuvveti, propriosepsiyon, denge, düşme ve vücut kompozisyonu arasındaki ilişkinin incelenmesidir.

Gereç ve Yöntemler: Çalışmamıza Tip 2 DM tanısı almış 35-65 yaş aralığında 40 hasta dahil edildi. Çalışmaya katılan hastaların açlık kan şekerleri, $\mathrm{HbA1c}$ ve B12 vitamin değerleri, hasta takip dosyalarından kaydedildi. Çalışma kapsamında hastalara alt ekstremite kas testi, diz eklemi propriosepsiyon değerlendirmesi, denge ve düşme değerlendirme testleri, vücut kütle indeksi değerlendirmeleri yapıldı. Bulgular: Sol diz $60^{\circ}$ fleksiyon pozisyon duyusu ile HbAlc arasında anlamlı ilişki bulundu ( $\mathrm{p}=0,026, \mathrm{rs}=0,352$ ). Sağ diz $60^{\circ}$ fleksiyon pozisyon duyusu ile APG arası anlamlı ilişki bulundu ( $\mathrm{p}=0,047, \mathrm{rs}=0,316)$. Kan glukoz seviyeleri ile denge, kas kuvveti ve vücut kompozisyonu arasında anlamlı ilişki bulunmadı.

Sonuç: Tip 2 DM tanılı hastaların alt ekstremite kas kuvvetinin ve diz propriosepsiyon duyularının iyi durumda olduğu ancak gözler kapatılıp görsel input ortadan kaldırıldığında daha çabuk denge kaybı gösterdikleri ve propriosepsiyon duyularının bu yönde etkilenmiş olduğu saptandı. Bu verilere dayanarak Tip $2 \mathrm{DM}$ tanılı hastalara denge egzersizlerinin tedavi programlarına erken dönemde eklenmesinin ileride yaşayacakları propriosepsiyon ve denge bozuklukları gibi durumlarda koruyucu etki göstereceğini düşünmekteyiz.
\end{abstract}

Anahtar Sözcïkler: Denge, Kas gücü, Propriosepsiyon, Tip 2 diyabet, Vücut Kompozisyonu

\section{Relationship Between Blood Glucose Level and Muscle Strength, Proprioception, Body Composition in Patients With Type 2 Diabetes}

\begin{abstract}
Aim: Our objective in this study is to demonstrate the relationship between blood glucose level and muscle strength, proprioception, balance-falling down and body composition in patients with type 2 diabetes.

Material and Methods: 40 type 2 diabetic patients age between 35-65 years were included into the study. Fasting blood glucose, HbA1c and B12 vitamin levels were recorded from the patients' files. Leg muscle strength, proprioception of knee joint, balance and fall tests, body composition were evaluated.

Results: Significant results found between left knee $60^{\circ}$ flexion propcioception and $\mathrm{HbAlc}$ and between right knee $60^{\circ}$ flexion propcioception with FPG ( $\mathrm{p}=0.026, \mathrm{rs}=0.352, \mathrm{p}=0.047 \mathrm{rs}=0.316$ ). There was no significant relation between blood glucose levels with balance, muscle strength and body composition.

Conclusion: We have found that diabetic patients have good leg muscle strength and knee proprioception, but while eyes were closed and when there is no visual input patients shown rapid lose of balance. According to this we came to the conclusion that their proprioceptions were affected in this way. We believe that the early addition of diabetic patient balance exercises to the treatment programs in this group will have a protective effect on future problems such as proprioception and balance disorders.
\end{abstract}

Key Words: Balance, Muscle strength, Proprioception, Type 2 diabetes, Body composition

ORCID: Zahide Betül Tayfur / 0000-0002-7403-1286, Esra Atılgan / 0000-0002-6381-5982 


\section{GİRIŞ}

Tip 2 DM; insülin direnci, bozulmuş insülin sekresyonu ve artmış glukoz üretimi ile karakterize heterojen bir grup bozukluğu içeren hastalıktır (1). Tip $2 \mathrm{DM}$ günümüzde gerek yaygınlığ komplikasyonlarla hâlâ en önemli mortalite ve morbidite nedenlerinden biridir (2).

Genellikle orta-ileri yaş hastalığ 1 olarak kabul edilmekle beraber, son yillarda 35-40 gibi erken yaşlarda da tip 2 DM vakaları görülmeye başlanmıştır (3). Bu durum özellikle günlük fiziksel aktivitedeki azalma, obezitedeki artı̧̧ ve yaşam tarzı değişiklikleri ile ilişkilendirilmektedir.

Hiperglisemi, vücutta yavaş ve uzun sürede gelişen bir tablo olduğu için komplikasyonlar tanı anında artık kronikleşmiş sorunlar olarak karşımıza çıkmakta ve bu kronikleşmiş problemler sağlık sistemi üzerinde ciddi ekonomik yük oluşturmaktadır (2,3). Son yayınlanan Uluslararası Diyabet Federasyonu (IDF) Diyabet Atlası'na göre ülkemiz Avrupa ülkeleri arasında tip 2 DM prevalansının en yüksek olduğu ülkedir.

Tip 2 DM'de kronik komplikasyonlar en fazla kardiyovasküler sistem, kas-iskelet sistemi ve sinir sistemini etkilemektedir $(4,5)$.

Sinir sistemi üzerinde özellikle meydana gelen nöropatiler, uyuşukluk, ayak ve cilt problemleri, görme problemleri, kas kuvvetinde azalma, propriosepsiyon kayıpları, antaljik yürüyüş, denge problemleri ve ciddi düşme problemlerini ortaya çıkarmaktadır $(4,5)$.

Obezite, koroner arter hastalı̆̆ı, inme, diabetes mellitus, hipertansiyon, yağ metabolizma bozuklukları gibi birçok hastalıkla birlikte seyreden bir durumdur. Obezite süresi uzadıkça tip 2 DM gelişme riski artmaktadır. Obezite tip 2 DM tanılı hastaların \% 85'inde görülür. Tip 2 DM’nin karın bölgesindeki yağlanmayla ilişkili olduğu bilinmektedir. Bu durum gövde esnekliğinin azalmasına ve denge kaybına yol açmaktadır $(1,4)$.

Razzak ve Hussein'in yaptığı çalışmada nöropatisi olmayan tip 2 DM tanılı ve sağlıklı iki grup, denge açısından karşılaştırılmış ve tip 2 DM tanılı grupta daha fazla denge kaybı görüldüğü saptanmıştır (6).

Timar ve ark.nın 198 Tip 2 DM tanılı ve nöropatili hastalar ile yaptığ testlerinin skorlarında negatif yönde artış olduğu görülmüştür (7).

Tip 2 DM'nin insan vücudunda bu şekilde sinsi ve derin tahribatından hareketle çalışmamızdaki amacımız; henüz nöropati tanısı konulmamış ancak tip $2 \mathrm{DM}$ tanısı ile yaşamakta olan hastalarda mevcut kan glukoz seviyeleri ile kas kuvveti, propriosepsiyon, denge, düşme ve obezite arasındaki ilişkiyi araştırmaktır.

\section{GEREÇ ve YÖNTEMLER}

Çalışmaya İstanbul Büyükşehir Belediyesi Şehzadebaşı Tip Merkezinin İç Hastalıkları Polikliniği'ne başvuran 35-65 yaş aralığında, 18 kadın 22 erkek toplam 40 Tip 2 DM tanılı hasta dahil edildi. Medipol Üniversitesi Girişimsel Olmayan Klinik Araştırmalar Etik Kurulu tarafından Karar No:10840098-604.01.01-E.3983 ile etik kurul onayı alındı. Çalışmaya dâhil edilenlerden gönüllü olduklarına dair aydınlatılmıs onam formu alındı.

Nörolojik hastalığı olan, görme-işitme kaybı olan, kooperasyonun sağlanamadığı hastalar ile yürümeye yardımcı cihaz kullanan, ayağında diyabetik ülseri olan ve genel nöropati varlığını belirlemek için dahiliye uzmanı tarafından oluşturulmuş 'hastaların el ve ayaklarında uyuşma, görme ve göz kapağına dair problemler ve ani ayağa kalkma durumunda göz kararması' varlığının sorgulandığı 3 soruluk ankete "evet" cevabı veren hastalar çalışmaya alınmadı.

Çalışmaya katılan tüm hastaların yaş, boy, kilo, vücut kütle indeksi ve hastalık süresi gibi demografik bilgileri alındı. Hastaların tip 2 DM açısından değerlendirilmesi amacıyla hasta takip dosyalarından diyabet tanı süreleri, açlık plazma glukoz değerleri, HbA1c ve B12 vitamin değerleri kaydedildi. Ayrica hastaların kas kuvveti, propriosepsiyon ve vücut kompozisyon değerlendirmeleri yapıldı.

Propriosepsiyon değerlendirmesinde, eklem pozisyon duyusu ölçümleri, $1^{\circ}$ duyarlılıktaki Baseline ${ }^{\bullet}$ marka, dijital gonyometre kullanılarak yapıldı. Test işlemi, hastalar prone pozisyonda yatırılarak uygulandi. Hastalar pozisyonlandıktan sonra diz $30^{\circ}, 45^{\circ}$ ve $60^{\circ}$ fleksiyon açlarına sırasıyla alınarak, hastalardan aynı noktaları tahmin etmeleri istendi. $\mathrm{Bu}$ ölçümler 3'er kez tekrarlanıp ortalaması kaydedildi. Ortalama değer hastaların tahmin ettiği açı ile gerçek açılar arasındaki fark olarak kaydedildi (8). Ortalama hata değeri proprioseptif duyu keskinliği ile ters orantılıdır (9).

Kas kuvveti değerlendirmesi Dr. Robert W.Lovett'in 0-5 arasinda puanlanan Manuel kas testi kullanılarak hamstringler, m. Quadriceps Femoris, m. Gastrocnemius ve Soleus, m.tibialis Anterior kasları değerlendirildi (10).

Denge değerlendirmelerinde tek bacak üzerinde durma testi (TBÜD), zamanlı kalk yürü testi (ZKYT) ve fonksiyonel uzanma testi (FUT) kullanıldı.

TBÜD testinde hastalardan bir bacaklarının üzerinde dengeli bir şekilde durmaları istendi. Gözler açıkken 30 saniye, gözler kapalıyken 60 saniye üst sinır olarak kabul edildi (11). Üst sınıra ulaşanların, havada olan ayağı yere 
dokunduranların veya dengesi bozulanların değerlendirme süresi sona erdirildi. Test her iki alt ekstremiteye de önce gözler açık sonra gözler kapalı olacak şekilde 3 kez uygulanarak en iyi skor kaydedildi. TBÜD testindeki süre ve skorlar yaşla yüksek oranda ilişkili olup yaşlanma ile azalmaktadır. TBÜD test süresindeki kısalma, azalmış denge fonksiyonu için bir belirteçtir. Süreye dayanan denge testlerinde, klinisyenin hasta için beklentisi yaşa dayanarak belirlenmelidir. 60-69 yaş arası sağlıklı bireyler en az 5 sn süreyle gözler açık olarak tek ayak üzerinde durabilmelidirler (12).

ZKYT ile hastaların denge, fonksiyonel mobilite ve performansları değerlendirildi. Hastalar yaklaşık $45 \mathrm{~cm}$ yüksekliğinde kolluksuz sandalyeye dik olarak oturtuldu. Sandalyeden 3 metre uzaklığa bir işaret konuldu. 'Başla' komutu ile hastaların oturdukları sandalyeden tutunmadan ayağa kalkarak işaretli noktaya kadar yürümeleri ve işaretli noktadan geri dönerek tekrar başladıkları noktaya ulaşıp aynı sandalyeye geri oturmaları istendi. Tüm süre kronometre ile kaydedildi. $\mathrm{Bu}$ işlem $3 \mathrm{kez}$ tekrarlanarak elde edilen sürelerin ortalaması alındı. Çalışmamızda hastalarımızın test skorları sayısal veri şeklinde değerlendirildi. Literatürde hastaların sayısal skorları aşağıda belirtildiği şekilde yorumlanmaktadır:

- $\quad$ <10 sn mobil, düşük düşme riski

- $\quad$ 10-20 sn, basit transferlerde bağımsız, orta düşme riski

- 20 sn günlük aktivitelerde bağımlı, yüksek düşme riski (13).

FUT ile hastaların statik denge değerlendirilmeleri yapıldı. $\mathrm{Bu}$ testte hastalardan duvara yan dönmeleri ve omuzu $90^{\circ}$ fleksiyona alarak, duvara yakın bir şekilde tutmaları istendi. Bu pozisyonda duvarda üçüncü parmak hizası işaretlendi. Hastalardan adım atmadan kol pozisyonunu koruyarak uzanabildikleri kadar öne uzanmaları istendi ve son noktada üçüncü parmak hizası yeniden işaretlendi. İki işaret arasındaki mesafe 'cm' birimi ile 'öne fonksiyonel uzanma mesafesi' olarak kaydedildi. Bu ölçüm hastaların hem sağ hem sol olmak üzere her iki taraflarında da üç kez tekrar edilerek uygulandı ve sonuçların ortalamaları kaydedildi $(8,10) .15$ $\mathrm{cm}$ ve $15 \mathrm{~cm}$ 'nin altı düşme riskinin önemli derecede arttığını, 15 ile $25 \mathrm{~cm}$. arası orta derecede düşme riski olduğunu göstermektedir (14).

Hastaların düşme değerlendirmesi, son 6 ay ve 1 yıl içinde dengelerini kaybederek düşüp düşmedikleri sorularak kaydedildi.

\section{İstatistiksel Analiz}

Örneklem büyüklügünü hesaplamak için literatür doğrultusunda incelenen Chiba ve ark.nın (15) çalışma verileri esas alınarak $G^{*}$ Power 3.1.9.4 programı kullanıldı. Gerçekleştiri- len analize göre örneklem büyüklügü \%90 güç için en az 38 olarak hesapland $1(\mathrm{~d}=0,44, \alpha=0.05)$.

Çalışmanın veri analizinde "SPSS (Statistical Package for Social Sciences) 21.0 istatistik programı kullanıldı. Çalışmanın biyoistatistiksel çözümlemesinde ele alınan ölçütler ortalama, standart sapma, frekans (n) ve yüzde(\%) değerleri ile tanımlandi.

Gruplarda yer alan değişkenlerin normal dağılıma uygunlukları "Shapiro-Wilks" testi ile değerlendirildi. Veriler Spearman korelasyon analizi ile incelendi. $\mathrm{p}<0,05$ olan değerler istatistiksel olarak anlamlı kabul edildi.

\section{BULGULAR}

Çalışmamıza 18 kadın 22 erkek toplam 40 hasta dahil edildi. Hastaların yaş ortalaması $50,72 \pm 7,43$ yıl olarak bulundu. Hastaların VKİ ölçüm ortalaması $31,02 \pm 4,12 \mathrm{~kg} / \mathrm{m}^{2}$ ve

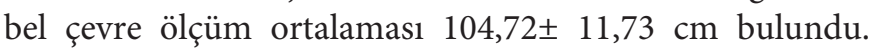
Tüm hastaların kan glukoz değerlerinin normal sınırların üzerinde olduğu görüldü (Tablo 1).

Tablo 2' de çalışmaya katılan hastaların açlık plazma glukoz seviyesi ve HbA1c değerleri ile sağ ve sol diz propriosepsiyon ölçümleri arası ilişki gösterildi. Sağ diz $60^{\circ}$ fleksiyon açısı ile açlık plazma glukoz seviyesi arasında $(\mathrm{p}=0,047, \mathrm{rs}=0,316)$ ve sol diz $60^{\circ}$ fleksiyon açısı ile $\mathrm{HbAlc}$ arasında pozitif ve zayıf düzeyde anlamlı ilişki bulundu ( $\mathrm{p}=0,026, \mathrm{rs}=0,352)$.

Hastaların açlık plazma glukoz seviyesi ve HbA1c değerleri ile sağ ve sol alt ekstremite kas kuvvetleri (quadriceps femoris kası, tibialis anterior kas1, gastrocnemius -soleus kas grubu, hamstring kas grubu) arasında anlamlı ilişkinin görülmediği Tablo 3’de gösterildi.

Tablo 4'de Çalışmaya alınan hastaların açlık plazma glukoz seviyesi ve HbA1c değerleri ile TBÜD gözler açık ve TBÜD gözler kapalı sağ ve sol taraf için anlamlı ilişki görülmedi. Hastaların açlık plazma glukoz seviyesi ve HbA1c değerleri ile ZKYT ve FUT değerlendirmeleri arasında anlamlı ilişki görülmediği Tablo 4' te gösterildi.

Hastaların açlık plazma glukoz seviyesi ve HbA1c değerleri ile düşme sonuçları, VKİ ve bel çevre ölçümleri arasında anlamlı ilişkiye rastlanmadığı Tablo 4' de gösterildi.

\section{TARTIŞMA}

Çalışmamızda diabetik nöropati tanısı almamış hastalarda, mevcut tip 2 DM varlığının kas gücü, propriosepsiyon ve vücut kompozisyonları üzerine olumsuz etkisi olmadığını gösterdik.

Literatüre baktığımızda yapılan çalışmalarda dengenin önemli unsurlarından biri olan propriosepsiyon duyusunun tip 2 DM tanılı hastalarda etkilenimi araştırılmıştır. 
Tablo 1: Hastaların demografik özellikleri diyabet tanı süreleri, plazma glukoz seviyeleri ve B12 düzeyleri.

\begin{tabular}{|c|c|}
\hline & Tanımlayıcı İstatistikler \\
\hline Cinsiyet K/ E n(\%) & $18(45) / 22(55)$ \\
\hline Yaş (yıl) ort \pm SS & $50,72 \pm 7,43$ \\
\hline Boy uzunluğu $(\mathrm{cm})$ ort $\pm S S$ & $166 \pm 7,92$ \\
\hline Vücut ağırlığı $(\mathrm{kg})$ ort $\pm S S$ & $86,52 \pm 13,11$ \\
\hline VKİ $\left(\mathrm{kg} / \mathrm{m}^{2}\right)$ ort $\pm S S$ & $31,02 \pm 4,12$ \\
\hline Bel Çevresi $(\mathrm{cm})$ ort $\pm S S$ & $104,72 \pm 11,73$ \\
\hline Dominant taraf R/L n (\%) & $38(95) / 2(5)$ \\
\hline Diyabet Süresi (yıl) ort \pm SS & $4,93 \pm 2,53$ \\
\hline APG $(70-100 \mathrm{mg} / \mathrm{dl})$ ort $\pm \mathrm{SS}$ & $172,92 \pm 68,32$ \\
\hline HbA1c (\%) ort \pm SS & $7,67 \pm 1,95$ \\
\hline B12 Vitamini $(120-700 \mathrm{pg} / \mathrm{ml})$ ort $\pm \mathrm{SS}$ & $409,40 \pm 189,39$ \\
\hline
\end{tabular}

ort: Ortalama, SS: Standart sapma, APG: Açlık plazma glikozu, HbA1c: Glikozillenmiş hemoglobin, cm: Santimetre, kg: Kilogram, VKİ: Vücut kütle indeksi, K: Kadın, E: Erkek, R: Right (sağ), L: Left (sol)

Tablo 2: Hastaların kan glukoz seviyeleri ile diz propriosepsiyonları arasındaki ilişki.

\begin{tabular}{cccccc}
\hline & D.F.Açısı & & \multicolumn{2}{c}{ APG (mg/dl) } & \multicolumn{2}{c}{ HbA1c(\%) } \\
\hline \multirow{2}{*}{$\mathbf{3 0}^{\circ}$} & & rs & p & rs & p \\
& Sağ & 0,063 & 0,699 & 0,062 & 0,705 \\
& Sol & $-0,007$ & 0,967 & 0,042 & 0,798 \\
\hline \multirow{2}{*}{$\mathbf{4 5}^{\circ}$} & Sağ & $-0,147$ & 0,364 & $-0,193$ & 0,232 \\
& Sol & 0,092 & 0,573 & 0,022 & 0,893 \\
\hline \multirow{2}{*}{$\mathbf{6 0}^{\circ}$} & Sağ & $\mathbf{0 , 3 1 6}$ & $\mathbf{0 , 0 4 7}$ & 0,281 & 0,079 \\
& Sol & 0,269 & 0,093 & $\mathbf{0 , 3 5 2}$ & $\mathbf{0 , 0 2 6}$ \\
\hline
\end{tabular}

rs: Spearman korelasyon kat sayısı, APG: Açlık plazma glukozu, HbA1c: Glikozillenmiş hemoglobin, D.F.Açısı: Diz fleksiyon açısı.

Tablo 3: Hastaların kan glukoz seviyeleri ile kas kuvvetleri arasındaki ilişki.

\begin{tabular}{lccccc}
\hline & & \multicolumn{2}{c}{ APG } & \multicolumn{2}{c}{ HbA1c(\%) } \\
\hline \multirow{2}{*}{ Hamstring } & & rs & p & rs & p \\
& Sağ & 0,237 & 0,141 & 0,182 & 0,262 \\
\multirow{2}{*}{ Q.femoris } & Sol & 0,200 & 0,217 & 0,114 & 0,483 \\
& Sağ & 0,139 & 0,391 & 0,161 & 0,322 \\
\multirow{2}{*}{ T.Anterior } & Sol & 0,072 & 0,661 & 0,074 & 0,650 \\
& Sağ & 0,130 & 0,423 & 0,048 & 0,771 \\
\multirow{2}{*}{ Gcm-soleus } & Sol & 0,130 & 0,423 & 0,048 & 0,771 \\
& Sağ & 0,084 & 0,605 & $-0,017$ & 0,917 \\
& Sol & 0,102 & 0,532 & 0,006 & 0,971 \\
\hline
\end{tabular}

rs: Spearman korelasyon kat sayıs1, APG: Açlık plazma glukozu, HbA1c: Glikozillenmiş hemoglobin, Gcm-sol. : Gastrocnemius - Soleus, Q.femoris: Quadriceps femoris kası, T.Anterior: Tibialis anterior kası.

Erduran'in (16) Tip 2 DM tanılı hastalarda, hastalık ve hastalık süresinin kas kuvveti ve propriosepsiyon duyusu üzerine etkisini değerlendirdiği çalışmasında 38 nöropatisiz tip 2 DM tanılı hastanın izokinetik dinamometre sistemi ile eklem pozisyon hissi ve kas kuvveti ölçümleri değerlendirilmiştir. Periferik nöropati gelişmemiş tip 2 DM tanılı hastalarda kas kuvveti kaybı gözlenmeksizin propriosepsiyon kaybı saptanmıştır. Çalışmamızda ise kas kuvveti ve 
Tablo 4: Hastaların kan glukoz seviyeleri ile denge parametreleri, düşme sonuçları ve vücut kompozisyonları arasındaki ilişki.

\begin{tabular}{|c|c|c|c|c|c|}
\hline & & \multicolumn{2}{|c|}{ APG(mg/dl) } & \multicolumn{2}{|c|}{ HbAlc(\%) } \\
\hline & & rs & $\mathbf{p}$ & rs & $\mathbf{p}$ \\
\hline \multirow{2}{*}{ TBÜD GA (sn) } & Sağ & $-0,156$ & 0,337 & $-0,246$ & 0,126 \\
\hline & Sol & $-0,114$ & 0,483 & $-0,119$ & 0,464 \\
\hline \multirow{2}{*}{ TBÜD GK (sn) } & Sağ & $-0,238$ & 0,139 & $-0,211$ & 0,191 \\
\hline & Sol & $-0,149$ & 0,359 & $-0,149$ & 0,357 \\
\hline FUT (cm) & & 0,016 & 0,922 & $-0,034$ & 0,833 \\
\hline ZKYT (sn) & & $-0,099$ & 0,544 & 0,033 & 0,840 \\
\hline Düşme 6 Ay & & 0,006 & 0,970 & $-0,012$ & 0,942 \\
\hline Düş̧me (1 Yıl) & & $-0,095$ & 0,558 & $-0,051$ & 0,753 \\
\hline VKİ $\left(\mathbf{k g} / \mathrm{m}^{2}\right)$ & & $-0,148$ & 0,363 & $-0,083$ & 0,612 \\
\hline BÇÖ (cm) & & $-0,003$ & 0,984 & 0,150 & 0,356 \\
\hline
\end{tabular}

rs: Spearman korelasyon kat sayısı, TBÜD GA: Tek bacak üzerinde durma testi gözler açık, TBÜD GK: Tek bacak üzerinde durma testi gözler kapalı, FUT: Fonksiyonel uzanma testi, ZKYT: Zamanlı kalk yürü testi, VKİ: Vücut kütle indeksi, BÇÖ: Bel çevre ölçümü, sn: Saniye, cm: Santimetre.

propriosepsiyon arasında anlamlı bir ilişki bulunamamıştır. $\mathrm{Bu}$ durumun hastalarımızın tip $2 \mathrm{DM}$ tanı sürelerinin kısa olmasından kaynaklandığını düşünmekteyiz.

Ng ve ark.nın (17) yaşıı tip 2 DM tanılı hastalarda ayak bileğinin fiziksel özellikleri ile mobilite performansını inceledikleri çalışmada ayak bileği propriosepsiyonu $10^{\circ}$ plantar fleksiyon açısında Cybex Norm dinamometre ile değerlendirilmiştir. Ayrıca ayak bileği dorsi ve plantar fleksiyon kas kuvvetleri ve eklem hareket açıları da değerlendirmeye alınmıştır. Hastaların hem eklem mobilitesinde hem de propriosepsiyonlarında azalma olduğu bulunmuştur. Bu çalışmada bizim çalışmamızdan farklı sonuçlar ortaya çıkmasının çalışmaya alınan hastaların, tip $2 \mathrm{DM}$ tanı sürelerinin daha uzun ve yaş ortalamasının daha yüksek olmasından kaynaklandığını düşünmekteyiz. Ayrıca bizim çalışmamızda diz propriosepsiyon ölçüm aracının farklı olmasının da ayrı bir etken olduğu kanaatindeyiz.

Çalışmamızda hastalarımızın diz propriosepsiyon duyusu ile kan glukoz seviyesi arasında sadece $60^{\circ}$ diz fleksiyon açısında ilişki bulundu. Erden'in (18) yaptığı çalışmada diz ekleminin, hata açısının $15^{\circ}$ den başlayarak $60^{\circ}$ ye kadar arttığı, en fazla değere bu derecede ulaştığ ve $90^{\circ}$ de yeniden azaldığı bulunmuştur. Bu durumu diz ekstansiyon pozisyonuna gelirken, antagonist kaslarda gerilim artışına paralel olarak daha fazla motor cevabın kas uyarılmasina bağlamışlardır. Çalışmamızda bulunan ilişkinin bu durumdan kaynaklandığını düşünmekteyiz. Ayrıca çalışmamızda $30^{\circ}$ ve $45^{\circ}$ diz fleksiyon pozisyon duyusu ile sol taraf gözler kapalı tek bacak üzerinde durma denge testi sonuçları arasında anlamlı ilişki bulundu. Hastalarımızın dominant taraflarının sağ oluşu ve görsel veri girişinin propriosepsiyonda önemli bir yere sahip olması nedeniyle böyle bir sonuca ulaşılmış olduğunu düşünmekteyiz.

Ferreira ve ark.nın (19) tip 2 DM tanılı hastalarda periferal nöropatinin alt ekstremite kas kuvvetine etkisini değerlendirdikleri çalışmada nöropatili ve nöropatisiz tip 2 DM tanılı hastaların diz ve ayak bileği kas grupları eksantrik, konsantrik ve izometrik olmak üzere izokinetik dinamometre ile değerlendirilmiştir. Tip 2 DM tanılı hastaların konsantrik ve izometrik kasılma kuvveti sağlıklı kontrollere göre daha düşük bulunmuştur. Bu çalışmadaki hastaların özellikleri ile bizim çalışmaya aldığımız hasta grubunun özellikleri her ne kadar benzer olsa da sonuçların farklı bulunmuştur. Bu durumun çalışmamızda manuel kas testi kullanmış olmamız ve kasılmanın tüm fazlarını değerlendirme şansımız olmayışından kaynaklandığını düşünmekteyiz.

Guerrero ve ark.nın (20) çalışmasında 100 (54 nöropatisi olan hasta) tip 2 DM tanılı hastada el sıkma kuvveti ve quadriceps kas kuvveti değerlendirilmiş ve diyabetik grubun değerleri sağliklı gruba oranla daha düşük çıkmıştır.

Almurdhi ve ark.nın (21) çalışmasında tip 2 DM tanılı hastalarda, diz ve ayak bileği kas grupları değerlendirilmiş, tip 2 DM tanılı hastaların değerleri anlamlı olarak düşük çıkmıştır. Yoon ve ark.nın (22) çalışmasında da diğer çalışmalara benzer sonuçlar elde edilmiştir. Bu çalışmalardan farklı sonuçlar elde etmiş olmamızın sebebinin literatürdeki çalışmalarda tip 2 DM tanılı hastaların, nöropatisi olan tip 2 DM tanılı hastaları da kapsiyor olmasindan kaynaklandığını düşünmekteyiz. Çalışmamıza özellikle nöropatisi olan hastalar dahil edilmemiştir. İlerleyen süreçteki çalışma- 
larda, nöropatisi olan ve olmayan tip 2 DM tanılı hastaların karşılaştırılmasına ihtiyaç vardır.

Daşkapan ve ark.nın (23) çalışmasında, hastalara yapılan ilk değerlendirmeler ve alt ekstremite güçlendirme egzersiz programı sonrası yapılan 2. değerlendirmeler, kas kuvvetindeki artışın, ZKYT skorlarını artırdığını göstermiştir. Bizim çalışmamızda da kas gücü ile dinamik denge arasında anlamlı sonuçlara ulaşılmıştır.

Özdirenç ve Algun (24) tip 2 DM tanılı hastalarda gözler açlk ve kapalı TBÜD testini değerlendirmişlerdir. Vaz ve ark. (25) tip 2 DM tanılı hastalarda, ZKYT ve gözler açı ve kapalı TBÜD testleri yapmışlardır. Çalışmamızda TBÜD testi gözler açık ve kapalı durma süreleri bu çalışmalar ile benzer skorları içermektedir.

Chiba ve ark.nın (15) çalışmasında tip 2 DM tanılı hastalar ve sağlıklı 2 grup arasında FUT ve ZKYT sonuçlarını karşılaştırmış ve sağlıklı bireylere oranla tip 2 DM tanılı hastaların skorlarının bozulduğu sonucuna ulaşılmıştır. Bizim çalışmamızda da benzer sonuçlara ulaşılarak tip 2 DM tanılı hastaların sağlıklı bireylere oranla, daha fazla denge problemi yaşadığı görülmüştür.

De Oliveira ve ark.nın (13) çalışmasında, çalışmamızla benzer yaş özelliklerine sahip hastalar çalışmaya alınmış ve ZKYT’nin değerlendirme aralıkları yine benzer çalışmalar örnek gösterilerek <10 sn. düşük düşme riski, 10-20 sn. arası orta düşme riski ve $>20$ sn yüksek düşme riski olarak belirlenerek tip $2 \mathrm{DM}$ tanılı hastaların orta ve yüksek riskli gruba dahil olduğu görülmüştür. Çalışmamızda hastaların düşük düşme riskli grupta olduklarını bulduk. Bu çalışmadan farklı sonuca ulaşmış olmamız, hastalarımızın tip 2 DM tanı sürelerinin kısa olması ve nöropatisiz tip 2 DM tanılı hastaları çalışmamıza dahil etmemizden kaynaklandığını düşünmekteyiz.

Schwartz ve ark.nın (26) yaptığı çalışmada yaş ortalaması 73,6 olan tip 2 DM tanılı hastalar, glisemik kontrol ve düşme açısından değerlendirilmiş ve uzun süreli tip 2 DM tanılı yaşlılarda denge bozukluğu ve düşmenin, diyabetik komplikasyonlar ile ilişkili olduğu bulunmuştur. Pijpers ve ark.nın (27) yaşlı tip 2 DM tanılı hastalarda 3 yıl boyunca yaptıkları düşme sorgulamasında yine diyabetin komplikasyonları ile ilişkili sonuçlara ulaşmışlardır. Bu çalışmalara karşın bizim çalışmamızda farklı düşme riski sonuçlarını elde etmemizin değerlendirmeye aldığımız grubun yaş ortalamasının genç ve hastalık süresinin daha kısa oluşundan kaynaklandığını düşünmekteyiz.

Çalışmamıza göre hastalarımızın kan glukoz seviyeleri ile diz propriosepsiyon duyusu arasinda sadece $60^{\circ}$ diz fleksiyon açısında ilişki bulundu. Hastalarımızın denge parametre sonuçlarının sağlıklı bireylere oranla düşük olduğu gözlendi ancak kan glukoz seviyesi ile anlamlı bir ilişki bulunmadı.

Çalışmamızın güçlü yanı literatürde daha çok ayak propriosepsiyonu üzerine çalışma yapıldı̆̆ı halde diz propriosepsiyonu üzerine yapılan çalışmaların sınırlı olmasıdır. Çalışmamızın zayıf yönü ise kontrol grubunun olmamasıdır.

İleride yapılacak benzer çalışmalarda daha fazla sayıda hasta ile kontrol grubu alınarak ve detaylı ölçüm araçları kullanılarak anlamlı sonuçlara ulaşılabilinir.

Diyabetik hastalara denge egzersizlerinin, tedavi programlarına özellikle erken dönemde eklenmesinin, ilerleyen dönemde yaşayabilecekleri propriosepsiyon ve denge bozukluklarında koruyucu etki göstereceğini düşünmekteyiz.

\section{Etik Kurul Onayı}

Çalışmamız için Medipol Üniversitesi Girişimsel Olmayan Klinik Araştırmalar Etik Kurulu tarafından Karar No:10840098604.01.01-E.3983 ile etik kurul onayı alındı. Çalışmaya dâhil edilen hastalardan gönüllü olduklarına dair aydınlatılmıs onam formu alınmıștır.

Çıkar Çatışması

Yazarlar arasında herhangi bir çıkar çatışması yoktur.

Finansal Destek

Çalışma için finansal destek yoktur.

Yazarların Makaleye Katkı Beyanı

Literatür taraması: Zahide Betül Tayfur, Denetim: Esra Atılgan, Veri Toplanması ve işlenmesi: Zahide Betül Tayfur, Analizler ve yorum: Zahide Betül Tayfur, Esra Atılgan, Makale yazımı: Zahide Betül Tayfur, Esra Atılgan, Eleştirel İnceleme: Esra Atılgan, Zahide Betül Tayfur.

Teșekkür

Bu çalışmayı yapmamızda bize ev sahipliği yapan İstanbul Büyükşehir Belediyesi Şehzadebaşı Tip Merkezi çalışanlarına ve İç hastalıkları Uzmanı Dr. Mehmet Tayfur 'a teșekkür ederiz.

\section{KAYNAKLAR}

1. Fauci AS, Braunwald E, Kasper DL, Hauser SL, Jameson JL, Longo DL, Loscalzo JL. Endokrinoloji ve metabolizma. Harrison's manuel of medicine. 17th ed. Mac Graw-Hill. 2009;942-947.

2. İliçin G, Biberoğlu K, Süleymanlar G, Ünal S. Cilt 2. Temel İç Hastalıkları. Ankara. Güneş Kitabevi; 2012. 2279-2302.

3. Satman İ. Tip 2 Diabetes Mellitus. Büyüköztürk K. İç Hastalıkları cilt 1. İstanbul. Nobel Kitabevi, 2007, 501-532.

4. Polat G, Diyabette Fiziksel Aktivite/Egzersiz, İstanbul. Marmara Üniversitesi, 2012 https://www.researchgate. net/publication/277571782_DIYABETTE_FIZIKSEL_ AKTIVITE_VE_EGZERSIZ / 20.08.2020 
5. Doğan D. Tip 2 Diyabetli Hastalarda Eğitim Düzeyi ile Diyabet Başlangıç Yaşı, Vücut Kitle İndeksi, HBA1C Düzey ve Mikroanjiyopatik Komplikasyonların Karşılaştırılması, T.C Sağlık Bakanlığı Haseki Eğitim ve Araştırma Hastanesi Aile Hekimliği, Uzmanlık Tezi, İstanbul, 2008 http://www. istanbulsaglik.gov.tr/w/tez/pdf/aile_hekimligi/dr_deniz_ dogan.pdf /20.08.2020

6. Razzak RA, Hussein W. Postural visual dependence in asymptomatic type 2 diabetic patients without peripheral neuropathy during a postural challenging task. J Diabetes Complications. 2016;30(3):501-506.

7. Timar B, Timar R, Gaiță L, Oancea C, Levai C, Lungeanu D. The impact of diabetic neuropathy on balance and on the risk of falls in patients with type 2 diabetes mellitus: A crosssectional study. PloS One. 2016;11(4):e0154654.

8. Gülbahar S, Akgün B, Karasel S, Baydar M, El Ö, Pınar $\mathrm{H}$, et al. Ön çapraz bağ rekonstrüksiyonu sonrası gelişen diz önü ağrısının kas kuvveti, fonksiyonel skorlar, denge ve propriosepsiyon üzerine etkisi. Türkiye Fiziksel Tip ve Rehabilitasyon Dergisi. 2013;59(2):90-96.

9. Dıraçoğlu D, Aydın R, Başkent A. Sağlıklı kişilerde ve diz osteoartritli hastalarda propriosepsiyon duyusunun karşılaştırılması. Turkiye Fiziksel Tip ve Rehabilitasyon Dergisi. 2005;1(51):90-93.

10. Otman AS, Köse N. Tedavi hareketlerinde temel değerlendirme prensipleri. 9. bask1. Ankara. Hipokrat Kitabevi, 2016, 120-192.

11. Ekizler S, Osman N, Aydın İS, Aliosmanoğlu A, Kara B. Alt ekstremite kas yorgunluğunun dengeye etkisi. Fizyoterapi Rehabilitasyon. 2006;17(3):127-133.

12. Soyuer F, Köseoğlu E. Dengenin klinik değerlendirilmesi. Erciyes Üniversitesi Sağlık Bilimleri Dergisi. 2001;10(2):75-82.

13. De Oliveira PP, Fachin SM, Tozatti J, Ferreira MC, Marinheiro LPF. Comparative analysis of risk for falls in patients with and without type 2 diabetes mellitus. Rev Assoc Med Bras. 2012; 58(2):234-239.

14. Duncan PW, Weiner DK, Chandler J, Studenski S. Functional reach: A new clinical measure of balance. J Gerontol. 1990; 45(6):192-197.

15. Chiba Y, Kimbara Y, Kodera R, Tsuboi Y, Sato K, Tamura Y, et al. Risk factors associated with falls in elderly patients with type 2 diabetes. J Diabetes Complications. 2015;29(7):898-902.

16. Erduran E. Tip 2 diabetes mellitus tanılı hastalarda hastalık ve hastalık süresinin kas kuvveti ve propriosepsiyon duyusu üzerine etkisi. Gazi Üniversitesi Tıp Fakültesi, Fiziksel Tıp ve Rehabilitasyon Anabilim Dalı, Tipta Uzmanlık Tezi, Ankara, 2015. https://tez.yok.gov.tr/UlusalTezMerkezi/ tezSorguSonucYeni.jsp /20.08.2020
17. Ng TKW, Lo SK, Cheing GLY. The association between physical characteristics of the ankle joint and the mobility performance in elderly people with type 2 diabetes mellitus. Archives of Gerontology and Geriatrics. 2014;59(2):346-352.

18. Erden Z. Dizin farklı açılarında eklem pozisyon hissi farklı midır? Joint Dis Rel Surg. 2009;20(1):47-51.

19. Ferreira JP, Sartor CD, Leal ÂM, Sacco IC, Sato TO, Ribeiro IL, et al. The effect of peripheral neuropathy on lower limb muscle strength in diabetic individuals. Clinical Biomechanics. 2017; 43:67-73.

20. Guerrero N, Bunout D, Hirsch S, Barrera G, Leiva L, Henríquez S, De la Maza MP. Premature loss of muscle mass and function in type 2 diabetes. Diabetes Res Clin Pract. 2016;117:32-38.

21. Almurdhi MM, Reeves ND, Bowling FL, Boulton AJ, Jeziorska M, Malik RA. Reduced lower-limb muscle strength and volume in patients with type 2 diabetes in relation to neuropathy, intramuscular fat, and vitamin D levels. Diabetes Care. 2016; 39(3):441-447.

22. Yoon JW, Ha YC, Kim KM, Moon JH, Choi SH, Lim S, et al. Hyperglycemia is associated with impaired muscle quality in older men with diabetes: The korean longitudinal study on health and aging. Diabetes Metab. 2016;40(2):140-146.

23. Daskapan A, Anaforoglu B, Pekyavas NO, Tuzun EH, Cosar $\mathrm{SN}$, Karatas M. Comparison of mini-squats and straight leg raises in patients with knee osteoarthritis: A randomized controlled clinical trial. Turkish Journal of Rheumatology. 2013;28(1):16-27.

24. Özdirenç M, Algun C. Tip 2 diabetes mellitusu olan olgularda yürüyüşün zaman-mesafe özellikleri. Fizyoterapi Rehabilitasyon. 2001;12(2):79-83.

25. Vaz MM, Costa GC, Reis JG, Junior WM, de Paula FJA, Abreu DC. Postural control and functional strength in patients with type 2 diabetes mellitus with and without peripheral neuropathy. Arch Phys Med Rehabil. 2013;94(12):2465-2470.

26. Schwartz AV, Vittinghoff E, Sellmeyer DE, Feingold KR, De Rekeneire N, Strotmeyer ES, et al. Diabetes-related complications, glycemic control, and falls in older adults. Diabetes Care. 2008;31(3):391-396.

27. Pijpers E, Ferreira I, de Jongh RT, Deeg DJ, Lips P, Stehouwer CD, Nieuwenhuijzen Kruseman AC. Older individuals with diabetes have an increased risk of recurrent falls: Analysis of potential mediating factors: The Longitudinal Ageing Study Amsterdam. Age and Ageing. 2012;41(3):358-365. 